\title{
Avaliação da suplementação de vitamina A nas características seminais em reprodutores suínos
}

\author{
Simone Maria Massami Kitamura Martins ${ }^{1}$, Abrão Antonio Ferreira Abrahão ${ }^{1}$, Wagner Loesch \\ Vianna $^{2}$, André Furugen Cesar Andrade ${ }^{2}$, Rubens Paes de Arruda ${ }^{3}$, Aníbal de Sant'Anna Moretti ${ }^{4}$ \\ ${ }^{1}$ Mestrando, Departamento de Nutrição e Produção Animal, FMVZ/USP. \\ 2 Doutorando, Departamento de Reprodução Animal, FMVZ/USP. \\ ${ }^{3}$ Departamento de Reprodução Animal, FMVZ/USP. \\ ${ }^{4}$ Departamento de Nutrição e Produção Animal, FMVZ/USP.
}

RESUMO - Avaliou-se o efeito da suplementação de vitamina A na dieta sobre as características seminais (volume, motilidade, $\mathrm{pH}$, vigor e concentração espermática, número total de espermatozoides, percentual de espermatozoides vivos e anormalidades morfológicas) de reprodutores suínos no período de um ano (junho de 2004 a junho de 2005). Utilizaram-se dez reprodutores híbridos com 328,5 \pm 2,12 dias de idade e 191,0 \pm 12,0 kg distribuídos em duas rações, uma controle, com 10.000 UI de vit. A por kg de ração por dia, e outra com 16.000 UI de vit. A, fornecidas na quantidade de $2,5 \mathrm{~kg} / \mathrm{dia}$. O delineamento foi inteiramente casualizado com medidas repetidas no tempo. Não houve efeito significativo da suplementação de vitamina $\mathrm{A}$ na dieta nem de interação com o tempo nas características seminais estudadas. O tempo teve efeito significativo no $\mathrm{pH}$, na concentração espermática, no número total de espermatozoides, no percentual de espermatozoides vivos, nas anormalidades morfológicas, na motilidade e no vigor espermático. Apesar da não-significância da suplementação de vitamina A, foi possível detectar diferenças numéricas no aumento da motilidade e de espermatozoides vivos, bem como na diminuição das anormalidades morfológicas, resultados que indicam ação da vitamina A.

Palavras-chave: cachaço, nutrição, sêmen, vitamina A

\section{Assessment of vitamin A supplementation on boar semen characteristics}

\begin{abstract}
The objective of this study was to evaluate the effect of vitamin A feed supplementation on the following boar semen characteristics: volume, motility, vigor, seminal $\mathrm{pH}$, spermatic concentration, total number of spermatozoa, percentage of living sperm cells and morphologic abnormalities. The experiment was carried out with 10 hybrid boars $(328.5 \pm 2.12$ days of age and $191.0 \pm 12.0 \mathrm{~kg}$ live weight). The boars were separated into two treatments and fed with two vitamin A levels: control, $10.000 \mathrm{UI} / \mathrm{kg}$ feed daily; and vitamin A, 16.000 UI. The boars received $2.5 \mathrm{~kg}$ feed daily. A randomized complete design was used with replication measurements in time. There was no significant effect of vitamin A supplementation on the characteristics studied, and nor on the time and treatment interaction. The was significant effect of time on $\mathrm{pH}$, spermatic concentration, total number of spermatozoa, percentage of living sperm cells, morphologic abnormalities, motility and vigor. Although detect significant differences were not detected between both treatments, numerical differences were detected indicating that vitamin A influenced the average increase in motility and the percentage of living sperm cells and the reduction in the percentage of morphologic abnormalities. Data showed support the idea that vitamin $\mathrm{A}$ is intimately associated with spermatogenesis.
\end{abstract}

Key Words: boar, nutrition, semen, vitamin A

\section{Introdução}

A suinocultura tem exigido averiguações mais aprofundadas da interação entre nutrição e reprodução. E o conhecimento dessa interação pode trazer benefícios na redução da idade à puberdade, melhoria da libido e do vigor sexual, e no desenvolvimento e manutenção das glândulas endócrinas (Close \& Cole, 2001).
Especificamente na espermatogênese, essa interação ganha relevância por se tratar de um processo que envolve a diferenciação das células germinativas e a expressão programada de diversos tipos e estágios de desenvolvimento celular. Entretanto, as mudanças morfológicas das células têm sido bem descritas, porém pouco se conhece sobre os mecanismos moleculares de regulação do gene envolvido neste evento reprodutivo (Lee et al., 2004). 
Medeiros \& Paulino (1999), relataram que a vitamina A é essencial para o crescimento e a proliferação de células epiteliais. Livera et al. (2002) descreveram que a vitamina atua ainda protegendo o epitélio germinativo de machos e estabilizando a integridade das membranas celulares. A ação é reforçada quando combinada com as vitaminas E e D (Martin-Rillo, 1982) e há evidências de que o betacaroteno, precursor da vitamina A, juntamente com o manganês e o zinco, estão envolvidos na esteroidogênese (Smith \& Akinbamijo, 2000).

As desordens reprodutivas observadas pela deficiência de vitamina A em animais de produção ocasionam atraso da puberdade, baixa taxa de concepção, alta mortalidade embrionária e libido reduzida nos machos (Smith \& Akinbamijo, 2000).

Em estudos com cachaços deficientes em vitamina A, foram observadas atrofia do testículo e mudanças qualitativas relacionadas à interrupção parcial ou total da espermatogênese (Palludan, 1963). De mesmo modo, foi observada em ratos com essa avitaminose redução da secreção dos níveis basais de testosterona (Appling \& Chytil,1981).

Em ratos, a deficiência de vitamina A induziu a parada da espermatogênese, resultando em túbulos seminíferos contendo somente células de Sertoli, espermatogônia e alguns espermatócitos (Unni et al., 1983). A espermatogênese pôde ser reiniciada pela utilização de retinol, resultando na sincronização do epitélio (Morales \& Griswold, 1987), sendo observadas taxas de desenvolvimento similares aos ratos normais (van Pelt \& Rooij, 1990).

O objetivo neste estudo foi avaliar a influência da suplementação de vitamina A na dieta sobre as características seminais de reprodutores suínos avaliadas durante um ano (junho de 2005 a junho de 2006).

\section{Material e Métodos}

O experimento foi conduzido no Laboratório de Pesquisa em Suínos da Faculdade de Medicina Veterinária e Zootecnia da Universidade de São Paulo - FMVZ/USP, Campus Pirassununga, São Paulo. Foram utilizados 10 machos adultos híbridos com 327 dias de idade e peso médio de $166 \mathrm{~kg}$, alojados individualmente em baias $\left(9,76 \mathrm{~m}^{2}\right.$ por animal) providas de bebedouros tipo chupeta e comedouros individuais.

Foram utilizados 10 reprodutores híbridos (Landrace $\times$ Large White) com aproximadamente 328 dias de idade e peso médio $191 \mathrm{~kg}$, alojados individualmente em baias. Na seleção dos animais, foram considerados a procedência, o grau de parentesco, a idade e o peso para melhor homogeneização da amostra.
Os animais foram distribuídos em duas dietas: uma controle, específica para machos reprodutores, com 10.000 UI de acetato de retinil (Rovimix ${ }^{\circledR}$, Roche) $/ \mathrm{kg}$, equivalente a 25.000 UI de acetato de retinil/animal.dia; e outra suplementada com acetato de retinil com 16.000 UI de acetato de retinil/kg, equivalente a 40.000 UI de acetato de retinil/ animal.dia, todas fornecidas na quantidade de $2,5 \mathrm{~kg} / \mathrm{dia}$. Utilizou-se o NRC (1998) como referencial para determinar os níveis de vitamina A utilizados em machos reprodutores (7600 UI de vitamina A para o consumo de 1,9 kg/dia).

O período experimental foi de junho de 2004 a junho de 2005. Foram realizadas 53 colheitas por animal, com intervalo de sete dias, totalizando 530 amostras. As colheitas foram realizadas pela manhã, na sala de colheita, com prévia higienização do prepúcio e empregando-se o método da mão enluvada (King \& Macpherson, 1973). Utilizou-se um becker previamente aquecido a $35^{\circ} \mathrm{C}$, adaptado com papelfiltro para acondicionamento do sêmen e separação das frações gelatinosa e líquida do ejaculado. O frasco foi protegido por um recipiente isotérmico e imediatamente após as colheitas, o sêmen foi analisado quanto às características volume, motilidade, $\mathrm{pH}$, vigor e concentração espermática, número total de células espermáticas no ejaculado, percentual de espermatozoides vivos e anormalidades morfológicas.

O volume do ejaculado foi mensurado no próprio frasco coletor e o $\mathrm{pH}$ do sêmen foi determinado utilizando-se peagâmetro. A motilidade e o vigor espermático foram avaliados no sêmen recém-coletado, com auxílio de microscópio ótico comum, com aumento de 100 x. Para análise da concentração espermática, foi utilizada a câmara de Neubauer, com o sêmen diluído na proporção de 1:99. A avaliação do percentual de espermatozoides vivos foi feita pela técnica de coloração eosina-nigrosina (Mies Filho, 1987). As anormalidades espermáticas foram preparadas em solução de formol salina acrescida de gotas de sêmen até a turvação. Realizaram-se a homogeneização e o preparo da amostra sem corante para avaliação das anormalidades morfológicas em microscópio de interferência diferencial, com aumento de $1000 \mathrm{x}$, em contagem diferencial de 300 células, avaliando-se acrossoma, cabeça, colo, peça intermediária, cauda, presença de gota e notificando o numero total de anormalidades (Scheid, 1993).

O delineamento experimental foi inteiramente casualizado, com o complemento do delineamento em medidas repetidas no tempo. Os dados obtidos dos procedimentos experimentais foram analisados utilizando-se o programa estatístico Statistical Analysis System (SAS Institute Inc., 1996), com prévia verificação da normalidade dos resíduos pelo teste de Shapiro-Wilk (PROC UNIVARIATE). As 
probabilidades de interações com o tempo foram determinadas pelo teste de Greenhouse-Geisser Epsilon. As análises por tempo somente foram realizadas quando as interações entre tempo e dieta não foram significativas. Para a análise do vigor espermático, utilizou-se a modelagem por cadeias de Markov (Ross, 2002) para estimar a probabilidade de transição ou manutenção do vigor (3-4 ou 4-4) do sêmen nos dois níveis de vitamina A na dieta. Para análise econômica do número de doses inseminantes por nível de vitamina A, adotaram-se apenas dados descritivos. Em todas as análises estatísticas, o nível de significância considerado foi de $5 \%$.

\section{Resultados e Discussão}

Os níveis distintos de vitamina A utilizados na dieta controle e naquela suplementada foram superiores aos recomendados pelo NRC (1998). Estudos demonstram pela interrupção parcial ou total da espermatogênese o grau de deficiência da vitamina A (Palludan, 1963).

Pesquisas de Kim \& Wang (1993) confirmam que a vitamina A age inclusive em determinados estágios da formação da célula espermática. O retinol, após sua transformação em ácido retinoico pelas células testiculares, participa da espermatogênese, promovendo a diferenciação espermática a adesão das células germinativas às células de Sertoli, e a liberação de espermatozoides no lúmen do túbulo seminífero (Vernet et al., 2006).

Essas considerações tornam-se relevantes para a análise da influência da vitamina A nas características seminais, confirmada em achados relacionados à análise do vigor espermático e da própria manutenção nessa condição aliado ao menor percentual de anormalidades morfológicas. Essas condições fundamentam a menor variabilidade da suplementação com 40.000 UI de acetato de retinil e indicam a ação da referida vitamina em machos reprodutores suínos.

$\mathrm{Na}$ análise da característica volume do ejaculado (Figura 1), não foi observada no estudo interação significativa entre tempo e suplementação, por isso, a análise dos fatores foi feita separadamente. Verificou-se, portanto, diferença significativa do fator tempo, independentemente do nível de vitamina A. Esse aumento gradativo do volume em ambos os níveis de vitamina A pode ser explicado pelo próprio estágio de desenvolvimento dos cachaços, que está relacionado, além da variação individual, ao aumento no volume do líquido seminal, principalmente oriundo da contribuição das glândulas anexas. A vitamina A na realidade não influenciou positivamente o volume, uma vez que sua ação está mais direcionada a proliferação e diferen- ciação das células germinativas presentes no túbulo seminífero que estimulando as glândulas sexuais acessórias.

Os resultados contrários verificados por Martin-Rillo (1982) indicam efeito positivo da vitamina A sobre o volume do ejaculado, mas não há relatos semelhantes na literatura.

Na característica motilidade (Figura 2), também não foi evidenciada diferença significativa na interação tempo e nível de vitamina A ( $\mathrm{P}=0,2666)$, o que comprova isoladamente efeito significativo de tempo e não-significativo da suplementação de vitamina A. Os valores de motilidade espermática foram de 67,0 \pm 8,06\% para a dieta controle e $79,0 \pm 5,40 \%$ para a dieta suplementada com vitamina A.
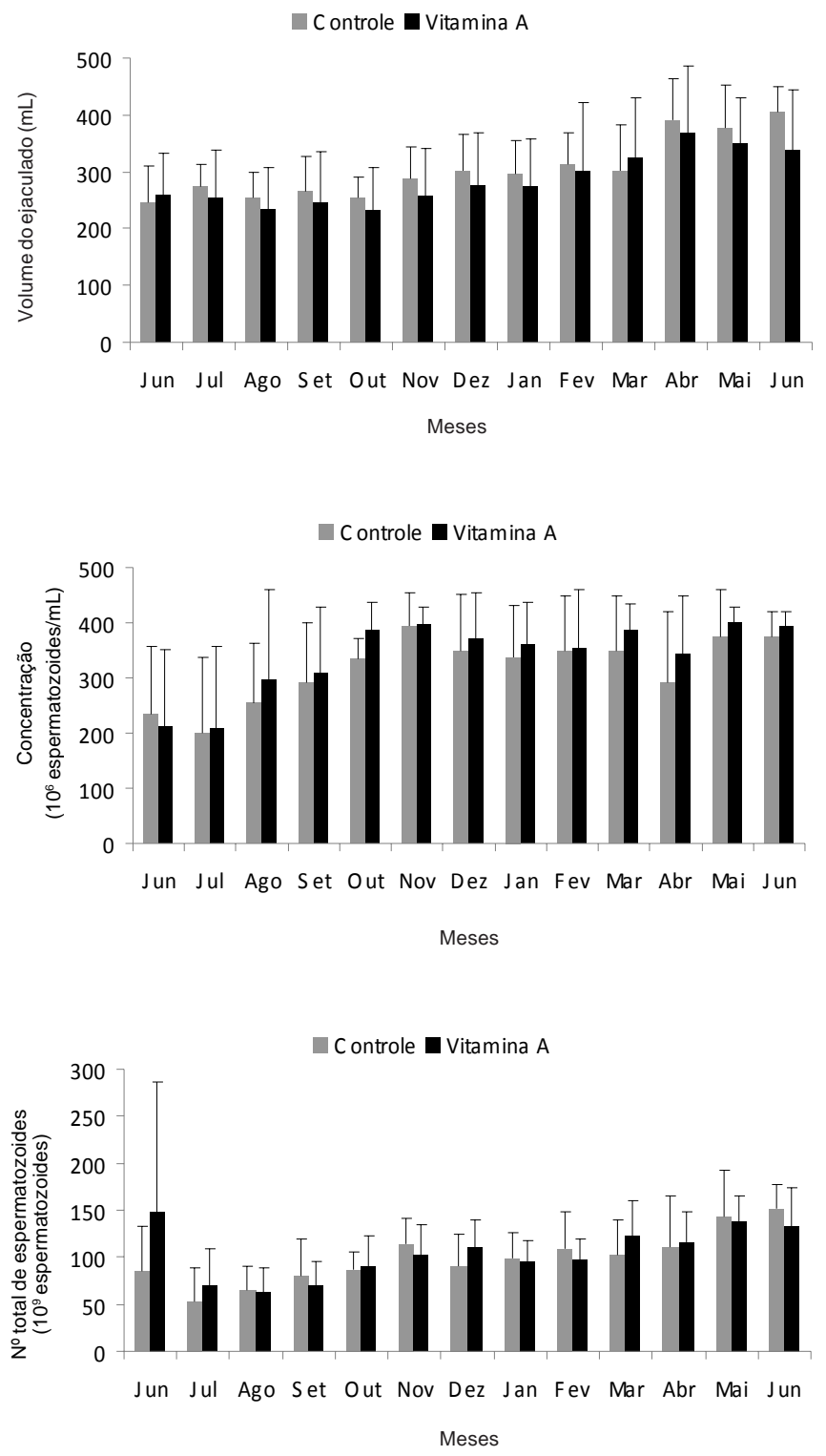

Figura 1 - Volume do ejaculado, concentração espermática e número total de espermatozoides $\left(10^{9}\right)$ no sêmen de reprodutores suínos sob suplementação com vitamina A. 

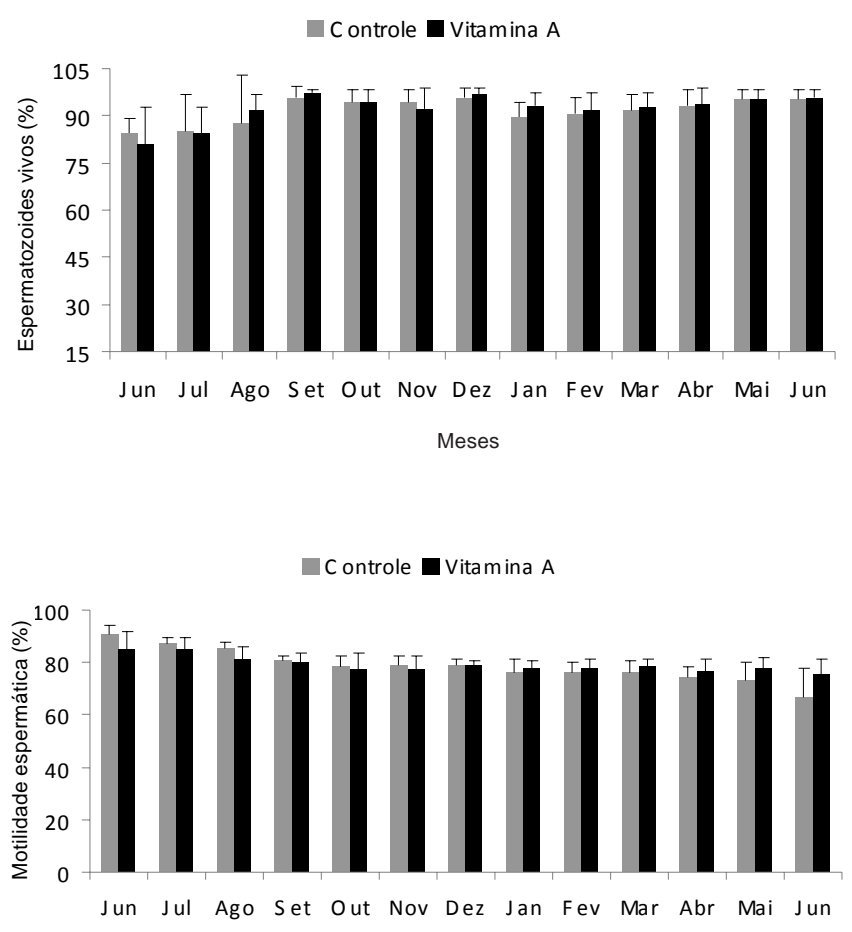

Meses
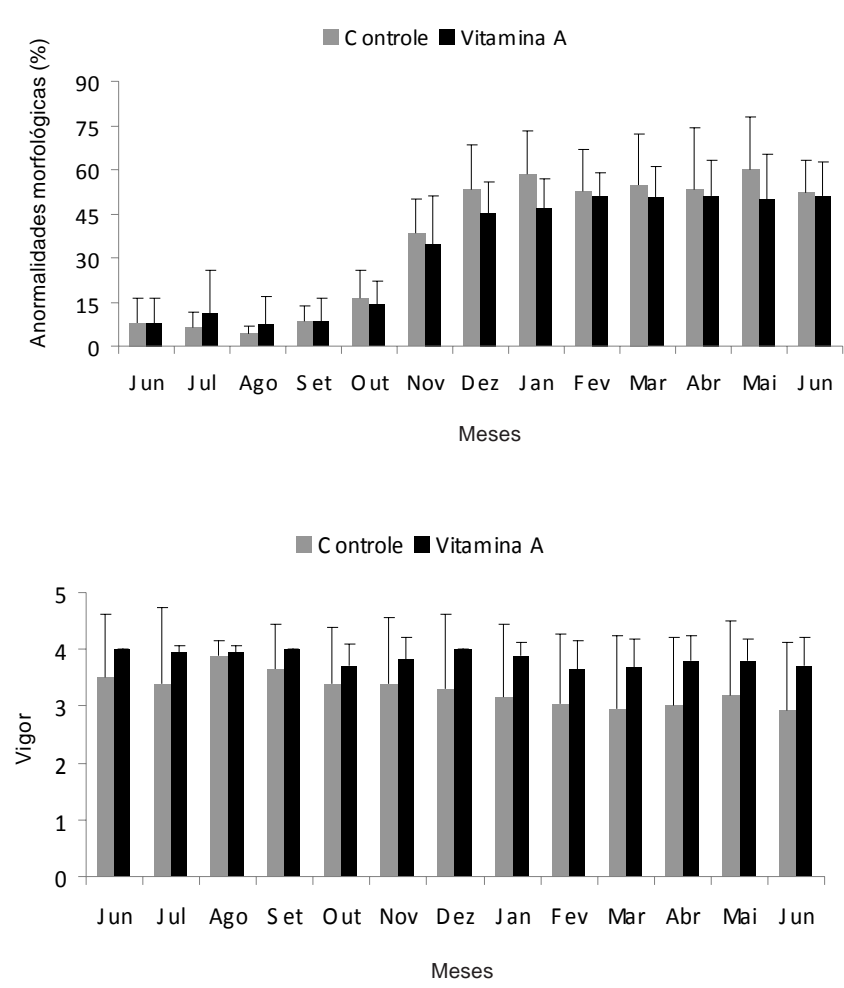

Figura 2 - Características morfológicas do sêmen de reprodutores suínos sob suplementação com vitamina A.

Esse resultado contraria os achados de Zervos et al. (2005), que avaliaram o efeito do acetato de retinil em ovinos (12.500 UI, 50.000 UI e 150.000 UI/animal) e também não observaram diferença significativa para essa característica seminal. Aikama et al. (2003), utilizando 100 UI acetato de retinol em ratos com deficientes de vitamina $\mathrm{A}$, verificaram efeito significativo, com redução dos distúrbios de motilidade.

Essa discordância está relacionada aos níveis de vitamina $\mathrm{A}$, muito distintos, o que não ocorreu neste estudo, conforme citado anteriormente. Comparativamente, Abrahão (2006), utilizando os mesmos níveis de suplementação por um período de 25 semanas, verificou efeito significativo da suplementação de vitamina A. Esse resultado deve ser interpretado considerando a menor idade dos animais, o menor período de análise, mas ao mesmo tempo, ser indicativo da ação da vitamina A, com base nos níveis idênticos ao deste estudo, o que justifica a sutil variabilidade nessa característica associada ao mecanismo de ação do ácido retinoico, conforme citado na literatura.

Com base nos valores médios percentuais de motilidade no período experimental descrito por Abrahão (2006), nota-se que houve diferença significativa entre as dietas controle e suplementada com vitamina A (73, $0 \pm 25,25 \%$ vs $83,0 \pm 7,53 \%$, respectivamente).
O resultado obtido para vigor espermático (Figura 2) foi semelhante ao da motilidade e não foi evidenciada diferença significativa na interação tempo $\times$ suplementação de vitamina A, o que indica apenas efeito significativo de tempo, e não da suplementação vitamínica. Os valores médios obtidos com a suplementação de vitamina $\mathrm{A}$ foram superiores ao da dieta controle durante o período experimental (3,3 $\pm 1,08$ vs $3,8 \pm 0,37$ controle e vitamina A, respectivamente.

Analisando a variabilidade pela modelagem por cadeias de Markov (Figura 3), constatou-se que a probabilidade da transição do vigor de 3-4 do controle era de 33\% e, para a vitamina $\mathrm{A}$, de $42 \%$, portanto, pelo menos neste experimento, a utilização da suplementação de vitamina A (40.000 UI) aumentou a capacidade de transição do vigor, pois esse maior percentual representou a maior chance de os animais de vigor 3 passarem para o vigor 4 de uma semana para outra. Esse mesmo efeito parece não ser tão evidente para os animais que já apresentavam vigor 4, pois a probabilidade de se manter é de $90 \%$ e de $92 \%$, respectivamente, para as dietas controle e com suplementação de vitamina A. Essa é uma evidência da menor variabilidade conferida pela vitamina A na formação da célula espermática, o que ratifica as considerações anteriormente relacionadas aos níveis empregados no estudo e à própria ação da vitamina A. 


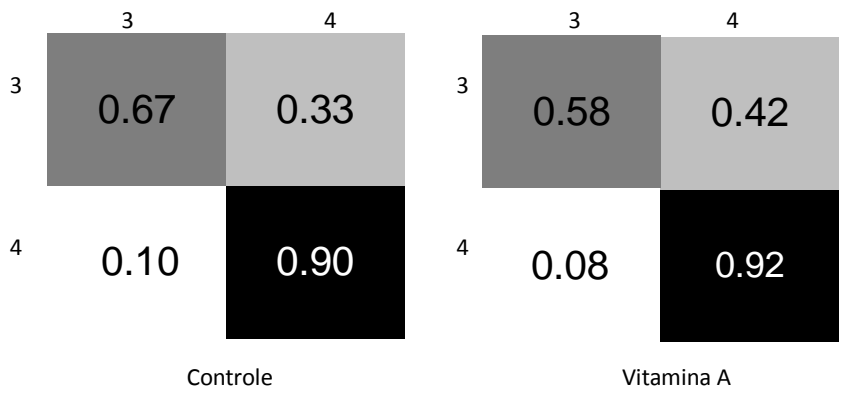

Figura 3 - Probabilidades de transição entre os estados de vigor espermático representada pela modelagem por cadeias de Markov.

$\mathrm{O}$ pH não diferiu significativamente com a interação tempo $\times$ suplementação com vitamina $A$, nem com a suplementação isoladamente; houve efeito apenas do tempo. Não foram evidenciadas diferenças entre dietas para os valores médios $(6,85 \pm 0,83$ vs $6,78 \pm 0,85$ para o controle e vitamina A, respectivamente); foram constatados valores diferenciados somente nos meses de novembro a janeiro. Provavelmente esse resultado se deve à resposta fisiológica do organismo ao passar por uma situação de estresse térmico (Torre et al., 2002).

Os valores obtidos com ambas as dietas encontram-se na variação considerada normal para o sêmen de reprodutores suínos (7,2 a 7,8) (Garner \& Hafez, 1995).

Na concentração espermática $\left(10^{6} / \mathrm{mL}\right)$, não foi evidenciada diferença significativa na interação tempo e suplementação vitamínica, o que comprova efeito significativo de tempo e não-significativo da suplementação. Os valores médios durante o período experimental foram de $324,03 \pm 11,83 \times 10^{6}$ vs $343,05 \pm 11,54 \times 10^{6}$ espermatozoides $/ \mathrm{mL}$ para o controle em comparação àquele com suplementação de vitamina A, respectivamente. Esses valores estão dentro da variação considerada normal para esta característica (200 a 400 x $10^{6}$ espermatozoides/mL) (Garner \& Hafez, 1995).

Estudos relacionados à deficiência de vitamina $\mathrm{A}$ em ratos comprovaram que a vitamina A bloqueia o estágio de espermatogônia, que é restabelecido após suplementação de retinoide (Unni et al., 1983; Livera et al., 2002).

Em grande parte do período experimental (60\%), a suplementação com vitamina A promoveu valores numericamente superiores aos obtidos com a dieta controle; o valor máximo foi obtido no mês de junho de 2005 (399 \pm $16,82 \times 10^{6}$ espermatozoides $/ \mathrm{mL}$ ) para a vitamina A e, no mês de novembro de 2004, o valor for de 394,5 $\pm 18,70 \times 10^{6}$ espermatozoides/mL correspondente ao controle, após redução da temperatura no mês de outubro (Figura 4).
O número total de espermatozoides no ejaculado (Figura 1) também não sofreu interação significativa tempo × suple-mentação vitamínica nem efeito da suplementação; apenas o tempo mostrou significância.

Apesar da não-significância, os valores médios da concentração espermática para a vitamina A superaram o controle; o volume foi maior para o controle, o que levou a um valor médio do número total de espermatozoides maior para o controle em comparação a vitamina A (102 $\pm 45,50$ x $10^{9}$ vs $99 \pm 51 \times 10^{9}$ espermatozoides, respectivamente).

Os resultados foram contrários aos encontrados por Abrahão (2006), que evidenciou efeito significativo da suplementação, mas, quando associado ao diferencial em relação ao volume, o estudo do autor revelou volumes maiores para a suplementação com vitamina A em comparação à ração controle, o que não ocorreu neste estudo.

Se observados os valores médios do número total de espermatozoides no ejaculado $\left(10^{9}\right)$ no período experimental, o resultado averiguado por Abrahão (2006) foi de $114 \pm 64,97 \times 10^{9}$ vs $122 \pm 72,56 \times 10^{9}$ de espermatozoides para o controle comparado ao suplementado com vitamina A; neste estudo, os valores foram de $102 \pm 45,50 \times 10^{9}$ vs $99 \pm 51 \times 10^{9}$ espermatozoides para o controle em comparação a vitamina A, respectivamente. Essa diferença a favor do controle pode estar relacionada ao maior valor numérico médio do volume ( $20 \mathrm{~mL})$, no controle, já que não houve diferença na concentração espermática. O comportamento desta característica foi muito semelhante para ambas as dietas.

No cálculo do número de doses inseminantes por nível de vitamina A avaliado (Figura 1), foram utilizados os valores médios do número total de espermatozoides no ejaculado (102 × $10^{9}$ espermatozoides vs $99,50 \times 10^{9}$ espermatozoides para o controle e vitamina A, respectivamente) e os valores médios de motilidade espermática

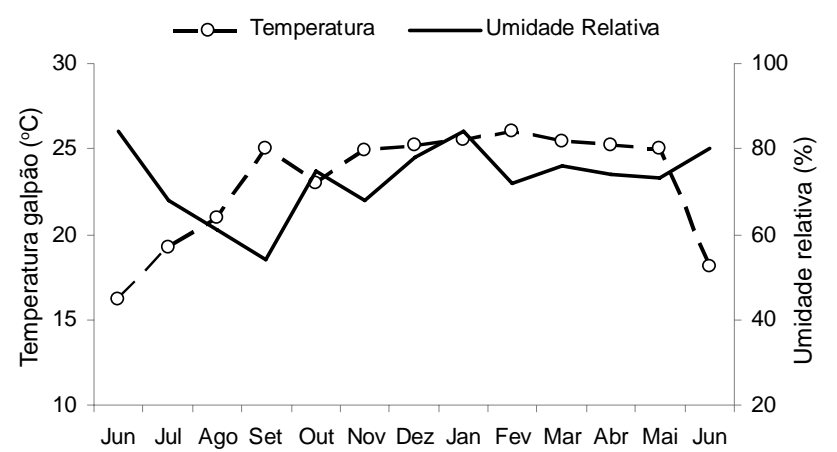

Figura 4 - Valores médios de temperatura do galpão $\left({ }^{\circ} \mathrm{C}\right)$ e umidade relativa do ar (\%). 
(67 vs 79\% para o controle e vitamina A, respectivamente), referente ao período experimental.

Considerando a concentração de $3 \times 10^{9}$ espermatozoides móveis por dose inseminante (Figura 1), seriam obtidas ao ano 1196 doses para o controle e 1352 para vitamina A. A cada semana, seriam produzidas em média 23 doses por animal no controle e 26 na vitamina A, o que corresponderia a 3 doses inseminantes/animal a mais para a dieta com vitamina A. Extrapolando esse aumento no número de doses inseminantes para uma central de inseminação que atende 3.500 matrizes, com 35 cachaços, numa relação 1:100 (1 reprodutor para 100 fêmeas), seriam obtidas 105 doses inseminantes a mais por semana. Considerando que o valor comercial de cada dose inseminante seja em torno de $\mathrm{R} \$ 6,00$ (seis reais), o lucro aparente obtido seria de $\mathrm{R} \$ 630,00$ (seiscentos e trinta reais) por semana. Ao ano esse valor seria o equivalente a R \$32.760,00 (trinta e dois mil setecentos e sessenta reais). Desse valor deveriam ser descontados os custos extras com aumento no número de bisnagas de sêmen, no diluente e antibiótico, na água deionizada e na suplementação de vitamina A na ração. O diferencial de 3 doses a mais equivale a uma redução em $12 \%$ de alojamento de machos. Para cada 100 machos, haveria uma redução de 12 machos, induzindo ao menor custo com instalações, manutenção, além de reduzir no custo com a alimentação e mão-de-obra. Uma outra associação a ser considerada é que, com o aumento do número de doses, há maior disseminação do material genético, na realidade, há uma fêmea inseminada a mais por semana/cachaço. Num plantel de 35 reprodutores, seriam 140 fêmeas a mais inseminadas por mês, o que aumentaria a produtividade geral do plantel.

O efeito da suplementação de vitamina A na formação da célula espermática sugere que o nível de 40.000 UI de vitamina A/animal.dia utilizado neste estudo é viável economicamente e inclusive já preconizado em determinadas indústrias que produzem núcleos de suplementos vitamínicos e minerais.

O percentual de espermatozoides vivos (Figura 2), determinado utilizando os corantes eosina-nigrosina, também não sofreu interação significativa entre tempo e nível de vitamina A nem efeito de suplementação; apenas efeito de tempo foi significativo. Foram pequenas as diferenças numéricas entre as dietas, e o percentual de espermatozoides vivos sofreu oscilação semelhante durante o período experimental.

Na característica anormalidades morfológicas (Figura 2), não houve interação significativa entre tempo e suplementação, nem efeito de suplementação; apenas o tempo foi significativo. Na maioria dos meses, 9 dos 13, a vitamina
A mostrou valores numéricos inferiores ao controle (70\%), lembrando a ação sutil pelos níveis utilizados no estudo e a relação com a integridade do epitélio.

O resultado deste estudo foi semelhante aos encontrados por Zervos et al. (2005), que também não verificaram diminuição nas anormalidades morfiológicas no sêmen de carneiros sob suplementação com acetato de retinil.

A variabilidade desta característica foi analisada por meio de técnicas de processos estocásticos, modelos lineraes mistos e inferência Bayesiana, nos quais o coeficiente negativo de comparação entre a 'vitamina A e controle' indicou que o percentual de anormalidades foi menor para a dieta com 40.000 UI de vitamina A que para a dieta controle $(\mathrm{P}=0,339)$. Esse resultado confirma o encontrado por Abrahão (2006), que verificou menores percentuais de anormalidades espermáticas para a dieta com vitamina A.

As diferenças numéricas neste estudo, associadas aos resultados verificados por Abrahão (2006), sugerem a continuidade dos estudos com esta vitamina, direcionando para a especificação de seus efeitos na menor variabilidade das características seminais.

No estudo ainda foram analisadas as variabilidades das características seminais aliadas ao fator estação do ano e principalmente nos meses quentes do ano (21/12/2004 a 20/3/2005). Detectaram-se diferenças significativas de estação do ano $(\mathrm{P}<0,001)$, caracterizando a sutil ação da vitamina A, justificada nos estágios intermediários de formação da célula espermática.

\section{Conclusões}

As características volume, motilidade, vigor espermático, $\mathrm{pH}$, concentração, número total de espermatozoides, percentual de espermatozoides vivos e anormalidades morfológicas não variam entre os níveis de vitamina $\mathrm{A}$ avaliados. As vantagens econômicas da suplementação de vitamina A consistem no maior número de doses inseminantes e na menor variabilidade obtida com a suplementação de vitamina A no nível de 40.000 UI/animal/dia.

\section{Agradecimentos}

Francine Taniguchi Falleiros, Sidney Franklin Araújo dos Santos e Maurício Frias Prata (DSM).

\section{Literatura Citada}

ABRAHÃO, A.A.F. Vitamina A na nutrição de cachaços: I - Fatores relacionados ao condicionamento de machos reprodutores suínos para a colheita de sêmen. II - Análise qualitativa e quantitativa do sêmen de cachaços submetidos 
à suplementação de vitamina A na dieta. 2006. 124f. Dissertação (Mestrado em Medicina Veterinária). Faculdade de Medicina Veterinária e Zootecnia/Universidade de São Paulo, Pirassununga, 2006.

AIKAWA, H.; KOYAMA, S.; MATSUDA, M. et al. Relief effect of vitamin $\mathrm{A}$ on the decreased motility of sperm and the increased incidence of malformed sperm in mice exposed neonatally to bisphenol A. Cell and Tissue Research, v.15, n.1, p.119-124, 2003.

APPLING, D.R.; CHYTIL, F. Evidence of a role for retinoic acid (vitamin A-acid) in the maintenance of testosterone production in male rats. Endocrinology, v.108, p.2120-2124, 1981.

CLOSE, W.H.; COLE, D.J.A. Nutrition of sows and boars. Loughborough: Nottingham University Press, 2001. 377p.

GARNER, D.L.; HAFEZ, E.S.E. Espermatozoides. In: HAFEZ, E.R. (Ed.) Reprodução animal. 6.ed. São Paulo: Manole, 1995. p.187-211.

KIM, K.H.; WANG, Z.O. Action of vitamin a on the testis: role of the Sertolli cell. In: RUSSELL, L.D.; GRISWOLD, M.D. (Eds.) The sertolli cell. Clearwater: Cache River Press, 1993. p.515-535.

KING, G.J.; MACPHERSON. J.W. A comparison of two methods for boar sêmen collection. Journal of Animal Science, v.36, n.4, p.563-565, 1973.

LEE, H.K.; YOO, M.S.; KWON, H.B. et al. Retinoic acids upregulate steroidogenic acute regulatory protein gene. Molecular and Cellular Endocrinology, v.148, p.1-10, 2004.

LIVERA, G.; ROUILlER-FABRE, V.; PAIRAULT, C. et al. Regulation and pertubation of testicular functions by vitamin A. Reproduction, v.124. p.173-180, 2002.

MARTIN-RILLO, R. Reproduccion e inseminacion artificial porcina. Madrid: Aedos, 1982. p.72-73.

MEDEIROS, R.M.T.; PAULINO, C.A. Vitaminas. In: SPINOSA, H.S.; GÓRNIAK, S.L.; BERNARDI, M.M. (Eds.) Farmacologia aplicada à medicina veterinária. 2.ed. Rio de Janeiro: Guanabara Koogan, 1999. p.541-554.

MIES FILHO, A. Reprodução dos animais domésticos e inseminação artificial. Porto Alegre: Sulina, 1987. v.5, 380p.
MORALES, C.R.; GRISWOLD, M.D. Retinol-induced stage synchronization in seminiferous tubules of the rat. Endocrinology, v.121, p.432-434, 1987.

NATIONAL RESEARCH COUNCIL - NRC. Nutrient requirements of swine. 10.rev.ed. Washington D.C.: National Academy of Sciences, 1998. 189p.

PALLUDAN, B. Vitamin A deficiency and its effect on the sexual organs of the boar. Acta Veterinaria Scandinavica, v.4, p.136-155, 1963.

ROSS, M.S. Introduction to probability models. 8.ed. New York: Academic Press, 2002. 775p.

SCHEID, I.R. Manual de inseminação artificial de suínos: procedimentos e métodos no laboratório. Concórdia: EMBRAPA-CNPSA, 1993. 48p.

STATISTICAL ANALYSIS SYSTEM - SAS. User's guide. release 6.12. Cary: SAS Institute, 1996. (CD-ROM).

TORRE, M.L.; FAUSTINI, M.; NORBERTI, R. et al. Boar semen controlled delivery system: analysis of batch seasonal variability. International Journal of Pharmaceutics, v.242, p.385-387, 2002.

SMITH, O.B.; AKINBAMIJO, O.O. Micronutrients and reproduction in farm animals. Animal Reproduction Science, v.60-61, p.549-560, 2000.

UNNI, E.; RAO, M.R.S.; GANGUL, Y.J. Histological an ultrastructural studies on the effect of vitamin A depletion and subseqüent repletion whit vitamin A on germ cells and Sertolli cells in rat testis. Indian Journal of Experimental Biology, v.21, n.4, p.180-192, 1983.

Van PELT, A.M.M.; ROOIJ, D.G. Synchronization of the seminiferous epithelium after vitamin A replacement in vitamin A-deficient mice. Biology of Reproduction, v.43, p.363-367, 1990.

VERNET, N.; DENNEFELD, C.; ROCHETTE-EGLY, C. et al. Retinoic acid metabolism and signaling pathways in the adult and developing mouse testis. Endocrinology, v.147, n.1, p.96-110, 2006.

ZERVOS, I.A.; TSANTARLIOTOU, M.P.; VATZIAS, G. et al. Effects of dietary vitamin A intake on acrosin- and plasminogenactivator activity of ram spermatozoa. Reproduction, v.129, p.707-715, 2005. 